\title{
Calcium Consumption During Pregnancy: A Multicenter Study in a Middle-Income Country in Southeast Asia
}

This article was published in the following Dove Press journal: International Journal of Women's Health

\author{
Panyu Panburana $\mathbb{D}^{\prime}$ \\ Ratana Komwilaisak (D) $^{2}$ \\ Fuanglada Tongprasert $\mathbb{D}^{3}$ \\ Podjanee Phadungkiatwattana ${ }^{4}$ \\ Ounjai Kor-anantakul ${ }^{5}$ \\ Pisake Lumbiganon $\left(\mathbb{I D}^{2}\right.$ \\ 'Department of Obstetrics \& \\ Gynecology, Faculty of Medicine, \\ Ramathibodi University Hospital, Mahidol \\ University, Bangkok, Thailand; \\ ${ }^{2}$ Department of Obstetrics \& \\ Gynecology, Faculty of Medicine, Khon \\ Kaen University, Khon Kaen, Thailand; \\ ${ }^{3}$ Department of Obstetrics \& \\ Gynecology, Faculty of Medicine, Chiang \\ Mai University, Chiang Mai, Thailand; \\ ${ }^{4}$ Rajavithi Hospital, Ministry of Public \\ Health, Bangkok, Thailand; ${ }^{5}$ Department \\ of Obstetrics \& Gynecology, Faculty of \\ Medicine, Songklanagarind Hospital, \\ Prince of Songkla University, Hat Yai, \\ Songkhla, Thailand
}

Correspondence: Panyu Panburana Department of Obstetrics \& Gynecology, Faculty of Medicine, Ramathibodi University Hospital, Mahidol University, Bangkok, Thailand

Email ppanburana@yahoo.com
Objective: To perform a cross-sectional observational study of calcium consumption among pregnant women from multicenter tertiary care hospitals in the middle-income country in Southeast Asia.

Study Design: A cross-sectional observational study.

Setting: The study was conducted in four geographical regions (northern, northeastern, southern, and central) of Thailand. Five participating hospitals consisted of one university hospital in each region and one additional tertiary care hospital in the central region.

Materials and Methods: A cross-sectional study was performed nationwide from $1 \mathrm{st}$ November 2017 to 31st January 2019. All singleton aged 19-40 years were included. Exclusion criteria were any conditions that influenced calcium-containing food consumption. Dietary intake self-records immediately after eating for two working days and one holiday were analyzed via INMUCAL-NV3.0 dietary program.

Results: The 1549 records were obtained. The mean age was $29 \pm 5.7$ years. Most participants were primigravida (48.6\%). The average gestational age was $20.6 \pm 8.8$ weeks. Mean calcium consumption was $602.4 \mathrm{mg} /$ day (95\% CI; $589.2615 .6 \mathrm{mg} /$ day) $\mathrm{mg} /$ dL. Inadequate calcium consumption prevalence based on the Thai dietary reference intake (less than $800 \mathrm{mg} /$ day) and US Institute of Medicine (less than $1000 \mathrm{mg} /$ day) were $82.0 \%$ and $93.4 \%$, respectively.

Conclusion: The mean calcium consumption among pregnant women in the middle-income country in Southeast Asia was $602.4 \mathrm{mg} /$ day (95\% CI 589.2-615.6 mg/day). Inadequate calcium consumption of Thai pregnant women prevalence was $82.0 \%$ and $93.4 \%$ according to Thai dietary reference intake in pregnancy and the US Institute of Medicine.

Keywords: calcium consumption, pregnancy, a middle-income country, Southeast Asia

\section{Introduction}

Calcium is an indispensable element for normal physiologic function, especially during pregnancy for both mothers and fetuses. ${ }^{1}$ The high fetal demand for calcium during pregnancy results not only in increasing maternal bone turnover but also in impacting on infants' bone density. ${ }^{2}$ There are pieces of evidence of the inverse relationship between calcium consumption and preeclampsia. ${ }^{3-5}$ Increased parathyroid hormone and 1,25-hydroxyvitamin D levels in low calcium-consumption mothers may come with intracellular calcium elevation that causes high blood pressure due to increased vascular muscle tone. ${ }^{6,7}$ Hypertensive disorder in pregnancy is one of the leading causes of maternal death, with a Maternal Mortality 
Ratio (MMR) of 3.5 per 100,000 live births in Thailand in $2018 .^{8}$ The analysis of the world health organization's multicountry survey on maternal and newborn health revealed preeclampsia incidence worldwide, and Thailand was $2.16 \%$ and $2.22 \%$, respectively, in $2013 .{ }^{9}$ World Health Organization recommended routine calcium supplementation from 20 weeks of pregnancy at doses of 1.5-2.0 g per day, particularly in a population with low calcium consumption to prevent preeclampsia. ${ }^{3} \mathrm{~A}$ recent systematic review and meta-analysis summarized that the mean calcium consumption in pregnancy in high-income countries (HICs) and low-and middle-income countries (LMICs) were $948.3 \mathrm{mg} /$ day (95\% CI $872.1-1024.4 \mathrm{mg}$ / day) and $647.6 \mathrm{mg} /$ day (95\% CI $568.7-726.5 \mathrm{mg} /$ day), respectively. This paper also reported that the incidences of calcium consumption below $800.0 \mathrm{mg} /$ day in HICs and LMICs were $29 \%$ and $82 \%$, respectively. ${ }^{6}$ Unfortunately, the data on calcium consumption in pregnant women across Thailand, which is now one of the middle-income countries in Southeast Asia, are still lacking. Only two studies reported calcium consumption incidence in some local areas of Thailand. ${ }^{10,11}$ The comprehensive information about calcium consumption in pregnancy is very important for policymakers to decide whether routine calcium supplementation during pregnancy is necessary or not. The National Health Security Office of Thailand is considering implementing calcium supplementation as a beneficial package for all Thai pregnant women. This study aimed to evaluate the calcium consumption of Thai pregnant women in four different regions of Thailand, which are different in geography and in culture and ways of life, especially in dietary intake.

\section{Materials and Methods Study Design}

A multicenter hospital-based, cross-sectional study from four geographical regions of Thailand was performed from 1st November 2017 to 31 st January 2019. This study was approved by the central research ethics committee (ref. no. CREC008/60BRm) and endorsed by each study site's hospital ethics committee. Written informed consent records were obtained from all participants. This study was conducted in accordance with the declaration of Helsinki.

\section{Setting}

The study was conducted in four geographical regions (northern, northeastern, southern, and central) of Thailand.
Five participating hospitals consisted of one university hospital in each region and one additional tertiary care hospital in the central region.

\section{Participants}

Participants were pregnant women who attended the antenatal care at the five participating hospitals from four geographic regions of Thailand during the study period. The study included pregnant women at the age of 19-40 years and all pregnancies of any ethnic groups, parities, education levels, and socio-economic statuses. Exclusion criteria were as follows: any conditions that hampered the calcium intake, history of calcium allergy, sarcoidosis, increased parathyroid gland activity, kidney stones, and decreased kidney function. Vegetarians were also excluded. We planned to recruit participants by trimester, $25 \%, 50 \%$, and $25 \%$ in the first, second, and third trimesters.

\section{Data Sources and Measurement}

Data collection was performed at the antenatal clinic by using a standardized dietary chart record. Prospective selfwritten dietary records of types and amount of raw material, ingredients, seasoning, as well as the names of a ready-to-eat dietary menu in two weekdays and one holiday, were performed. Trained research nurses identified eligible participants among women who attended antenatal care clinic using inclusion and exclusion criteria described above. They then explained to eligible participants on how to record the dietary charts correctly. Diaries of what, when, and how much food was eaten were demonstrated via food illustration and quantity measurement. With an accurate summary of food record, error associated with memory was minimized by the immediate record after eating each day. The research nurses checked for the completeness of the data record. After knowing the quantity of calcium consumption, the result was informed back to each participant. The food composition information for each participant was analyzed by the INMUCALNutrients program of the Institute of Nutrition, Mahidol University, Bangkok, Thailand. ${ }^{12,13}$ This INMUCALNutrients program is an automatic program for calculating or transferring the weight of cooked food to raw food ingredients and according to the cooking method using cooking conversion factor. ${ }^{14}$

\section{Sample Size and Statistical Analysis}

When the prevalence of inadequate calcium consumption during pregnancy of $55 \%$ from the previous study ${ }^{10}$ with 
an acceptable error of 5\% and an alpha error of 5\% was taken into account, at least 381 participants were required for each region. The descriptive statistics were used to describe demographic characteristics, presented as mean, standard error (SE) or $95 \%$ confidence interval (CI), median, and range for describing continuous data. Frequency and percentage were used to describe categorical data. Linear regression analysis was used to assess the association between demographic factors and the amount of calcium intake. All data processing was performed using Stata V15.0 Stata Corp LLC 4905 Lakeway Drive College Station, Texas 77,845-4512 USA. The p-value of less than 0.05 was considered statistically significant.

\section{Results}

There were 1549 participants recruited for this study; 404 , 404, 415, and 326 participants from central, northern, northeastern, and southern regions, respectively (Figure 1). The main characteristics of all participants are revealed in Table 1. The mean age was $29 \pm 5.7$ years. Most participants were primigravida (48.6\%). The average gestational age was $20.6 \pm$ 8.8 weeks. The mean prepregnant BMI was $21.8 \pm 3.3 \mathrm{~kg} / \mathrm{m}^{2}$. The median income was 18,000 (1000-250,000) Baht* [\$562.5 (31.0-7812.5) ]* (one Dollar = 32.0 Baht). About half of the participants' educational level was a Bachelor's degree (53.1\%). Participants from the four regions were quite comparable in maternal age, gestational age, gravidity, prepregnant BMI, education level, and income. Table 2 demonstrates the mean calcium consumption across the country was $602.4 \mathrm{mg} /$ day (95\% CI 589.2-615.6 mg/day). Pregnant women in the northern region had the highest calcium consumption/day at $625.1 \mathrm{mg} /$ day ( $95 \%$ CI $600.0-650.2 \mathrm{mg} /$ day), while the central region had the second-highest calcium consumption/day at $621.2 \mathrm{mg} /$ day ( $95 \%$ CI $593.9-648.5 \mathrm{mg} /$ day). The calcium consumption/day in the northeastern region was $602.1 \mathrm{mg} /$ day (95\% CI 576.6-627.6 mg/day). While the pregnant women in the southern region had the lowest calcium consumption/day $(551.3 \mathrm{mg} /$ day; $95 \%$ CI $524.3-578.3 \mathrm{mg} /$ day) (Table 2). The prevalence of total calcium consumption less than $500 \mathrm{mg} /$ day, less than $800 \mathrm{mg} /$ day, and less than $1000 \mathrm{mg} /$ day was $37.7 \%, 82.0 \%$, and $93.4 \%$, respectively. The average calorie intake was $1448.8 \mathrm{kcal} /$ day $(95 \% \mathrm{CI}$ 1429.4-1468.2 kcal/day) (Table 2).

The association between daily calcium consumption and maternal age, gestational age (GA), prepregnant BMI, educational levels, calorie intake, income are demonstrated in Table 3. In the 2nd trimester and 3rd trimester, pregnant women had calcium consumption higher than those in the 1st trimester, 61.4 and $66.2 \mathrm{mg} /$ day, respectively. Participants with pre-pregnant BMI between $26-30 \mathrm{~kg} / \mathrm{m}^{2}$ and $>30 \mathrm{~kg} / \mathrm{m}^{2}$ had mean calcium consumption less than participants with pre-pregnant BMI less than $18 \mathrm{~kg} / \mathrm{m}^{2} 85$ and $110.4 \mathrm{mg} /$ day, respectively. Participants with a calorie intake of more than $1500 \mathrm{Kcal} /$ day had significantly higher calcium consumption than those with calorie intake $\leq 1500 \mathrm{kcal} /$ day. There was no significant difference in calcium consumption across all levels of participants' income. Interestingly, when milk or soybean consumption units/day in term of bottles/boxes/ glasses taken into account, the incidences of no consumption, one-unit/day consumption, and more-than-one unit/day

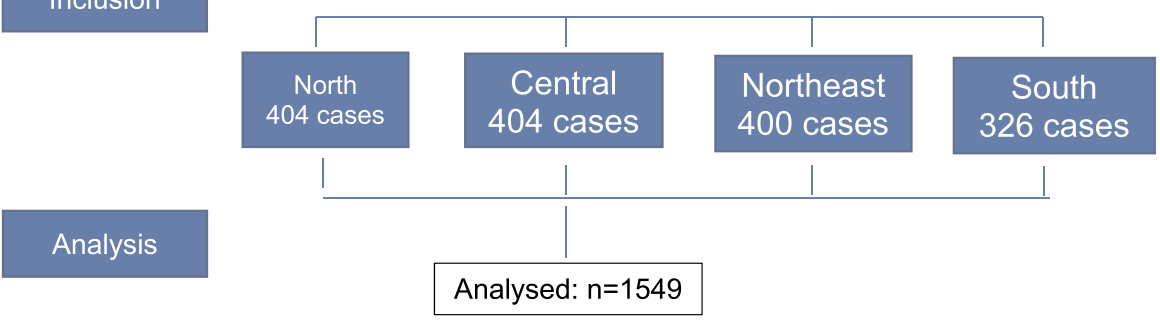

Figure I Flow diagram of study participants. 
Table I Demographic Profile

\begin{tabular}{|c|c|c|c|c|c|}
\hline \multirow[t]{2}{*}{ Characteristics } & Central Region & Northern Region & $\begin{array}{l}\text { Northeastern } \\
\text { Region }\end{array}$ & Southern Region & $\begin{array}{l}\text { Total Four Regions } \\
\text { of Thailand }\end{array}$ \\
\hline & $\begin{array}{l}\text { Ramathibodi + } \\
\text { Rajavithi (Bangkok) }\end{array}$ & Chiang Mai & Khon Khaen & Songkhla & Five Study Centers \\
\hline Number of participants & 404 & 404 & 415 & 326 & 1549 \\
\hline $\begin{array}{l}\text { Age (years), n (\%) } \\
\qquad \begin{array}{l}19-24 \\
25-34 \\
\geq 35\end{array}\end{array}$ & $\begin{array}{l}103(25.5) \\
216(53.5) \\
85(21.0)\end{array}$ & $\begin{array}{l}97(24.0) \\
24 \mid(59.7) \\
66(16.3)\end{array}$ & $\begin{array}{l}102(24.6) \\
245(59.0) \\
68(16.4)\end{array}$ & $\begin{array}{l}72(22.1) \\
178(54.6) \\
76(23.3)\end{array}$ & $\begin{array}{l}374(24.1) \\
880(56.8) \\
295(19.1)\end{array}$ \\
\hline Mean (SD) & $29.1(6.0)$ & $28.5(5.4)$ & $28.9(5.4)$ & $29.9(5.8)$ & $29.0(5.7)$ \\
\hline $\begin{array}{l}\text { Gravida, n (\%) } \\
\quad \text { । } \\
2 \\
3 \\
\geq 4\end{array}$ & $\begin{array}{l}190(47.0) \\
128(31.7) \\
57(14.1) \\
29(7.2)\end{array}$ & $\begin{array}{l}208(51.5) \\
138(34.2) \\
41(10.2) \\
17(0.1)\end{array}$ & $\begin{array}{l}182(43.9) \\
168(40.5) \\
54(13.0) \\
11(2.7)\end{array}$ & $\begin{array}{l}173(53.1) \\
89(27.3) \\
42(12.9) \\
22(6.8)\end{array}$ & $\begin{array}{l}753(48.6) \\
523(33.8) \\
194(12.5) \\
79(5.1)\end{array}$ \\
\hline Mean (SD) & $18(1.0)$ & $1.7(0.8)$ & $1.8(0.8)$ & $1.7(1.0)$ & $1.8(0.9)$ \\
\hline Median (Range) & $2(1,5)$ & I $(I, 5)$ & $2(1,8)$ & I $(I, 7)$ & $2(1,8)$ \\
\hline $\begin{array}{l}\text { Gestational age at data colle } \\
\text { (weeks), n (\%) } \\
\quad<13 \\
13-28 \\
\geq 29\end{array}$ & $\begin{array}{l}77(19.1) \\
248(61.4) \\
79(19.6)\end{array}$ & $\begin{array}{l}80(19.1) \\
237(58.7) \\
87(21.5)\end{array}$ & $\begin{array}{l}95(22.9) \\
228(54.9) \\
92(22.2)\end{array}$ & $\begin{array}{l}70(21.5) \\
143(43.9) \\
113(34.7)\end{array}$ & $\begin{array}{l}322(20.8) \\
856(55.2) \\
371(24.0)\end{array}$ \\
\hline Mean (SD) & $21.0(8.1)$ & $20.0(8.3)$ & $19.0(9.3)$ & $21.9(9.4)$ & $20.6(8.8)$ \\
\hline $\begin{array}{l}\text { Prepregnant BMI }\left(\mathrm{kg} / \mathrm{m}^{2}\right), \mathrm{n} \\
\quad<18 \\
18-25 \\
26-30 \\
>30\end{array}$ & $\begin{array}{l}19(4.7) \\
319(79.0) \\
59(14.6) \\
7(1.7)\end{array}$ & $\begin{array}{l}20(5.0) \\
346(85.6) \\
38(9.4) \\
0(0.0)\end{array}$ & $\begin{array}{l}33(8.0) \\
328(79.0) \\
51(12.3) \\
3(0.7)\end{array}$ & $\begin{array}{l}23(7.0) \\
246(75.5) \\
52(16.0) \\
5(1.5)\end{array}$ & $\begin{array}{l}95(6.1) \\
1239(80.0) \\
200(12.9) \\
15(1.0)\end{array}$ \\
\hline Mean (SD) & $22.2(3.5)$ & $21.4(2.8)$ & $21.7(3.3)$ & $21.9(3.6)$ & $21.8(3.3)$ \\
\hline $\begin{array}{l}\text { Level of education, n (\%) } \\
\text { Primary school } \\
\text { Secondary school } \\
\text { Vocational school } \\
\text { Bachelor's degree } \\
\text { Master's degree }\end{array}$ & $\begin{array}{l}18(4.5) \\
161(39.9) \\
60(14.9) \\
145(35.9) \\
20(5.0)\end{array}$ & $\begin{array}{l}5(1.4) \\
105(29.2) \\
26(7.2) \\
211(58.6) \\
13(3.6)\end{array}$ & $\begin{array}{l}2(0.6) \\
107(31.4) \\
22(6.5) \\
188(55.1) \\
22(6.5)\end{array}$ & $\begin{array}{l}10(3.5) \\
50(17.3) \\
19(6.6) \\
184(63.7) \\
26(9.0)\end{array}$ & $\begin{array}{l}34(2.5) \\
420(30.6) \\
108(7.9) \\
728(53.1) \\
81(5.9)\end{array}$ \\
\hline $\begin{array}{l}\text { Income Baht(US Dollar)/mo } \\
\text { n }(\%) \\
\quad<10,000(\$ 3 \mid 2.5) \\
\quad 10,000(\$ 3 \mid 2.5)-20,000 \\
(\$ 625.0) \\
\quad>20,000(\$ 625.0)\end{array}$ & $\begin{array}{l}49(12.1) \\
97(24.0) \\
258(63.9)\end{array}$ & $\begin{array}{l}185(45.8) \\
155(38.4) \\
64(15.8)\end{array}$ & $\begin{array}{l}181(43.6) \\
135(32.5) \\
99(23.9)\end{array}$ & $\begin{array}{l}124(38.0) \\
113(34.7) \\
89(27.3)\end{array}$ & $\begin{array}{l}539(34.8) \\
500(32.3) \\
510(32.9)\end{array}$ \\
\hline $\begin{array}{l}\text { Median (Baht }(\$) \\
\text { Range: } \min -\max (\operatorname{Baht}(\$))\end{array}$ & $\begin{array}{l}25,000(\$ 781.2) \\
2000(\$ 62.5)-250,000 \\
(\$ 78 \mid 2.5)\end{array}$ & $\begin{array}{l}15,000(\$ 468.8) \\
3000(\$ 93.8)- \\
200,000(\$ 6250.0)\end{array}$ & $\begin{array}{l}15,000(\$ 468.8) \\
1500(\$ 46.9)-80,000 \\
(\$ 2500.0)\end{array}$ & $\begin{array}{l}16,000(\$ 500.0) \\
1000(\$ 31.2)- \\
100,000(\$ 3125.0)\end{array}$ & $\begin{array}{l}18,000(\$ 562.5) \\
1000(\$ 3 \mid .2)-250,000 \\
(\$ 78 \mid 2.5)\end{array}$ \\
\hline
\end{tabular}

consumption were detected $85 \%, 14 \%$, and $1 \%$, respectively, group, there were the incidences of $5 \%, 60 \%, 35 \%$ of no in low calcium consumption $(<800 \mathrm{mg} /$ day $)$ group. consumption, one-unit/day consumption, and more-than-one Regarding adequate calcium consumption ( $\geq 800 \mathrm{mg} /$ day) unit/day consumption, respectively. 
Table 2 Regional Total Calorie and Calcium Intake Distribution Across the Country

\begin{tabular}{|c|c|c|c|c|c|}
\hline $\begin{array}{l}\text { Geographical Regions of } \\
\text { Thailand }\end{array}$ & Central Region & $\begin{array}{l}\text { Northern } \\
\text { Region }\end{array}$ & $\begin{array}{l}\text { Northeastern } \\
\text { Region }\end{array}$ & $\begin{array}{l}\text { Southern } \\
\text { Region }\end{array}$ & All Regions \\
\hline \multirow[t]{2}{*}{ Study sites (cases) } & $\begin{array}{l}\text { Ramathibodi + Rajavithi } \\
\text { (Bangkok) }\end{array}$ & Chiang Mai & Khon Khaen & Songkhla & $\begin{array}{l}\text { Five study } \\
\text { centers }\end{array}$ \\
\hline & 404 & 404 & 415 & 326 & 1549 \\
\hline \multicolumn{6}{|l|}{ Total calorie intake, Kcal/d n $(95 \% \mathrm{Cl})$} \\
\hline$\leq 1500$ & $57.9(52.9,62.8)$ & $64.9(60.0,69.5)$ & $58.8(53.9,63.6)$ & $59.2(53.7,64.6)$ & $60.2(57.7,62.7)$ \\
\hline$|50|-2500$ & $40.1(35.3,45.1)$ & $34.9(30.3,39.8)$ & $39.8(35.0,44.6)$ & $40.4(35.1,46.0)$ & $38.7(36.3,41.2)$ \\
\hline $250 I-3500$ & $1.5(1.0,3.2)$ & $0.2(0.006,1.4)$ & $1.4(0.1,0.3)$ & $0.3(0.01,1.7)$ & $0.9(0.5,1.5)$ \\
\hline$>3500$ & $0.5(0.1,3.2)$ & $0(0.0)$ & $0(0.0)$ & $0(0.0)$ & $0.1(0.02,0.5)$ \\
\hline Mean $(95 \% \mathrm{Cl})$ & $\begin{array}{l}14,474.7 \\
(14,429.6,14,519.8)\end{array}$ & $\begin{array}{l}1404.8 \\
(1372.6,1437.0)\end{array}$ & $\begin{array}{l}1472.2 \\
(1436.1,1508.3)\end{array}$ & $\begin{array}{l}1441.5 \\
(1400.7,1482.3)\end{array}$ & $\begin{array}{l}1448.8 \\
(1429.4,1468.2)\end{array}$ \\
\hline \multicolumn{6}{|l|}{ Total calcium intake $\mathrm{mg} / \mathrm{d}, \mathrm{n}(95 \% \mathrm{Cl})$} \\
\hline$\leq 500$ & $35.6(31.0,40.5)$ & $32.4(27.9,37.2)$ & $37.3(32.7,42.2)$ & $47.2(41.7,52.8)$ & $37.7(35.3,40.1)$ \\
\hline $50 \mathrm{I}-799$ & $44.1(39.2,49.1)$ & $47.8(42.8,52.8)$ & $45.1(40.2,50.0)$ & $38.7(33.3,44.2)$ & $44.2(41.6,46.7)$ \\
\hline $800-999$ & $10.6(7.8,14.1)$ & $14.4(11.1,18.2)$ & $10.6(7.8,14.0)$ & $9.5(6.6,13.2)$ & $11.4(9.8,13.0)$ \\
\hline $1000-1499$ & $7.9(5.5,11.0)$ & $4.7(2.9,7.2)$ & $5.8(3.7,8.4)$ & $4.0(2.1,6.7)$ & $5.7(4.6,7.0)$ \\
\hline $1500-2499$ & $1.7(0.1,3.5)$ & $0.5(0.1,1.8)$ & $1.2(0.4,2.7)$ & $0.6(0.1,2.1)$ & $1.0(0.1,1.7)$ \\
\hline$\geq 2500$ & $0(0.0)$ & $0.2(0.006,1.4)$ & $0(0.0)$ & $0(0.0)$ & $0.06(0.0002,0.4)$ \\
\hline Mean $(95 \% \mathrm{Cl})$ & $\begin{array}{l}621.2 \\
(593.9,648.5)\end{array}$ & $\begin{array}{l}625.1 \\
(600.0,650.2)\end{array}$ & $\begin{array}{l}602.1 \\
(576.6,627.6)\end{array}$ & $\begin{array}{l}551.3 \\
(524.3,578.3)\end{array}$ & $\begin{array}{l}602.4 \\
(589.2,615.6)\end{array}$ \\
\hline
\end{tabular}

\section{Discussion}

Our data from all regions across Thailand elucidated the high prevalence of low calcium consumption. It is the level that calcium supplements should be beneficial in reducing the risk of preeclampsia.

The result from Songklanagarind Hospital, Prince of Songkla University in the southern part of Thailand, showed the lowest calcium consumption. The previous study in the deep south of Thailand also revealed the low calcium consumption in pregnant women. ${ }^{10}$ On the contrary, our result from Srinagarind Hospital, Khon Kaen University in the northeastern part of Thailand revealed the inadequacy of calcium consumption, which had an opposite result from the previous study. ${ }^{11}$ This discrepancy result from this center might be due to the different methods used for assessing calcium consumption. According to the World Bank Classification of country income, the United Nations region, Thailand is one of the middleincome countries. The mean calcium consumption during pregnancy of low-and middle-income countries was $647.64 \mathrm{mg} /$ day (95\% CI 568.71-726.57 mg/day) while that of high-income countries was $948.28 \mathrm{mg} /$ day $(95 \%$ CI $872.10-1024.57 \mathrm{mg} /$ day). ${ }^{6}$ Our data demonstrated that the daily calcium consumption of Thai pregnant women was $602.4 \mathrm{mg} /$ day (95\% CI 589.2-615.6 mg/day), which was lower than the mean calcium consumption of low-and middle-income countries around $7.51 \%$ and lower than the mean calcium consumption of high-income countries $57.42 \%$. When comparing with calcium consumption of pregnant women in our middle-income neighboring countries such as Malaysia, Thailand had a lower amount of calcium consumption by $3.98 \%$. $^{15}$

\section{Strength}

This study was conducted in all major geographical regions of Thailand to assess the regional variation. The results from all regions were the same (low mean calcium consumption and high inadequate intake rates). These indicate the results' robustness. Evaluating the calcium consumption by the 3-day dietary intake immediate records ( 2 weekdays and 1 holiday) is also our study strength. We used the guidance of food records monitored by well-trained research nurses to ensure an accurate result. Once obtaining dietary information, the data were analyzed by experienced nutritionists using INMUCAL-NV3.0 program from the nutritional Institute, Mahidol University, Thailand. This program is suitable for Thai-style food as it was developed by collecting nutritive database values of Thai food consumption and recipes and can be compared with Thai Dietary Reference Intake (DRI). ${ }^{14}$ This program provides 
Table 3 Association Between Calcium Intake and Some Maternal Characteristics

\begin{tabular}{|c|c|c|c|c|}
\hline Factors & Mean of Calcium Intake mg/day & SE & Coef. $(95 \% \mathrm{Cl})$ & P-value \\
\hline \multicolumn{5}{|l|}{ Age (years) } \\
\hline $19-24$ & 614.8 & 21.7 & 0 & \\
\hline $25-35$ & 584.9 & 19.1 & $-29.8(-61.6,1.9)$ & 0.065 \\
\hline$\geq 35$ & 643.5 & 22.8 & $28.7(-11.5,68.9)$ & 0.161 \\
\hline \multicolumn{5}{|l|}{ Gravida } \\
\hline 1 & 588.3 & 19.7 & 0 & \\
\hline 2 & 607.9 & 20.8 & $19.6(-9.7,48.9)$ & 0.189 \\
\hline 3 & 652.6 & 25.5 & $64.3(-22.9,105.6)$ & 0.080 \\
\hline$\geq 4$ & 598.4 & 34.1 & $10.1(-50.7,70.8)$ & 0.745 \\
\hline \multicolumn{5}{|l|}{ Gestational age (weeks) } \\
\hline$<12$ & 553.7 & 21.7 & 0 & \\
\hline $12-27$ & 615.0 & 18.3 & $61.4(27.7,95.0)$ & $<0.00 I^{*}$ \\
\hline$\geq 28$ & 619.9 & 21.0 & $66.2(27.2,105.3)$ & $0.00 I^{*}$ \\
\hline \multicolumn{5}{|l|}{ Pregnant BMI $\left(\mathrm{kg} / \mathrm{m}^{2}\right)$} \\
\hline$<18$ & 648.5 & 31.9 & 0 & \\
\hline $18-25$ & 607.9 & 18.7 & $-40.5(-95.2,14.1)$ & 0.146 \\
\hline $26-30$ & 563.4 & 25.2 & $-85.0(-148.9,-21.1)$ & $0.009 *$ \\
\hline$>30$ & 538.1 & 69.7 & $-110.4(-253.1,-32.3)$ & $0.01 *$ \\
\hline \multicolumn{5}{|l|}{ Level of education } \\
\hline Less than bachelor degree & 620.6 & 20.2 & 0 & \\
\hline Bachelor degree or higher & 587.4 & 20.1 & $-33.2(-60.2,6.1)$ & 0.16 \\
\hline \multicolumn{5}{|l|}{ Income (Baht(US Dollar)/month) } \\
\hline$<10,000(\$ 312.5)$ & 623.1 & 21.0 & 0 & \\
\hline $10,000(\$ 312.5)-20,000(\$ 625)$ & 575.2 & 20.9 & $-47.9(-79.9,16.0)$ & 0.50 \\
\hline$>20,000(\$ 625)$ & 610.8 & 20.7 & $-12.3(-46.6,22.0)$ & 0.482 \\
\hline \multicolumn{5}{|l|}{ Total calorie intake (Kcal/d) } \\
\hline$\leq 1500$ & 523.9 & 14.7 & 0 & \\
\hline$|50|-2500$ & 715.9 & 15.8 & $192.0(166.8,217.2)$ & $<0.00 I^{*}$ \\
\hline $250 I-3500$ & 1035.3 & 66.0 & $511.4(383.3,639.5)$ & $<0.001 *$ \\
\hline$>3500$ & 413.6 & 171.9 & II $0.3(106.9,226.2)$ & $<0.05^{*}$ \\
\hline
\end{tabular}

Note: *Statistical significance.

the accurate evaluation of many sorts of nutrients, especially from regional Thai food and recipe and the userfriendly program, which is approved to be one of the standard programs in a multicenter study in Thailand. ${ }^{16}$

\section{Limitation}

The university and tertiary care hospital study centers mostly covered the well-developed areas of the country in this study. Therefore, the result might not represent the whole actual prevalence of low calcium consumption across the country. However, even the well- to -do group of pregnant women still have low calcium consumption. We suspect that the figure must be even worse for the general population. In the southern region, we could not recruit participants according to the target sample size because there were not enough women at the antenatal care clinic of the university hospital. Gestational age, prepregnant BMI, and calorie intake were the main maternal characteristics of calcium consumption inadequacy. Nausea \& vomiting during early pregnancy and calorie intake restriction in pregnancy with obesity influenced calcium consumption during gestation. The further study should focus on the amount of vitamin D consumption, parathyroid hormone, and the 1.25 - hydroxy vitamin $\mathrm{D}$ levels in the low calcium consumption mothers and the incidence of preeclampsia after calcium supplementation across the country.

These research findings strongly encourage not only pregnant women and medical personnel but also the national policymakers to realize the dietary low calcium 
consumption situation in Thailand. Our study demonstrated a high prevalence of low calcium consumption among all income levels. A recent systematic review and meta-analysis also indicated the high prevalence of lowcalcium consumption in pregnancy in LMICs and HICs. Regarding the mean calcium consumption/day in LMICs (600 $\mathrm{mg} /$ day), the increase in calcium consumption around 400-500 $\mathrm{mg} /$ day might help to attain values close to current calcium consumption recommendations for pregnancy. There are three broad approaches to improve dietary intake: one is behavioral interventions that, although ideal, rely on personal habits and ability; the second is a supplementation that targets individuals; and the third is a fortification, which aims to improve the dietary intake of the whole population. ${ }^{17}$

Lifestyle interventions during antenatal care improve gestational weight, calorie, mineral, vitamins, trace elements, and calcium consumption, especially in middleand low-income countries. ${ }^{18,19}$ According to our study, at least one unit/day of milk/soybean consumption should be encouraged in pregnancy to meet the adequate calcium requirement. The pregnant women's attitude should also be the critical factor that can be adjusted to realize the importance of calcium consumption during pregnancy and the source of calcium in food. Therefore, health literacy about adequate perinatal nutrition, especially calcium, is very important for good antenatal care. The healthcare team should emphasize and embed this knowledge into daily practice. A pragmatic approach to dietary calcium management needs to be considered and implemented among the middle-income countries in Southeast Asia.

In conclusion, the mean calcium consumption among pregnant women in Thailand, which is considered one of the middle-income countries in Southeast Asia, was $602.4 \mathrm{mg} /$ day (95\% CI 589.2-615.6 mg/day). According to Thai dietary reference intake in pregnancy and the international recommendation, the prevalence of inadequate calcium consumption of Thai pregnant women was $82.0 \%$ and $93.4 \%$.

Author contributions: All authors contributed to data analysis, drafting or revising the article, have agreed on the journal to which the article will be submitted, gave final approval of the version to be published, and agree to be accountable for all aspects of the work.

\section{Data Sharing Statement}

All the data are held at Ramathibodi University Hospital, Mahidol University. The data sharing can be allowed by contacting the coordinating author with the relevant ethics committee approval.

\section{Acknowledgments}

We sincerely thank all the participants and staffs from all study sites. We should also owe Professor Pisake Lumbiganon for his encouragement and advice with an outstanding debt of gratitude. Sincere thanks also go to Thailand Research Fund (Distinguished Research Professor Award) for financial support.

\section{Disclosure}

The authors report no conflicts of interest in this work.

\section{References}

1. WHO. Guideline: Calcium Supplementation in Pregnancy Women. 2013:1-30

2. Zeni SN, Oretela SCR, Lazzari A, et al. Interrelationship between bone turnover markers and dietary calcium intake in pregnant women: a longitudinal study. Bone. 2003;33(4):606-613. doi:10.1016/S87563282(03)00203-5

3. WHO. Recommendations on Antenatal Care for a Positive Pregnancy Experience. Luxembourg: WHO Press; 2016:152.

4. Hofmeyr GJ, Lawrie TA, Atallah AN, Torloni MR. Calcium Supplementation During Pregnancy for Preventing Hypertensive Disorders and Related Problems (Review). 2018:1-121.

5. Omotayo MO, Dickin KL, O'Brien KO, Neufeld LM, De Regil LM, Stoltzfus RJ. Calcium supplementation to prevent preeclampsia: translating guidelines into practice in low-income countries. $A d v$ Nutr. 2016;7(2):275-278. doi:10.3945/an.115.010736

6. Cormick G, Betrán AP, Romero IB. Global inequities in dietary calcium intake during pregnancy: a systematic review and meta-analysis. BJOG. 2019;126(4):444-456. doi:10.1111/14710528.15512

7. Repke JT, Villar J, Anderson C, Pareja G, Dubin N, Belizan JM. Biochemical changes associated with blood pressure reduction induced by calcium supplementation during pregnancy. Am J Obstet Gynecol. 1989;160(3):684-690. doi:10.1016/S0002-9378(89)800596

8. Ministry of Public Health. Public Health Statistics A.D.2018. Bangkok, Thailand;2018:142.

9. Abalos E, Cuesta C, Carroli G. Preeclampsia, eclampsia and adverse maternal and perinatal outcomes: a secondary analysis of the World Health Organization multicountry survey on maternal and newborn health. BJOG. 2014;121:14-24. doi:10.1111/14710528.12629

10. Sukchan P, Liabsuetrakul T, Chongsuvivatwong V, Songwathana P, Sornsrivichai V, Kuning M. Inadequacy of nutrients intake among pregnant women in the deep south of Thailand. BMC Public Health. 2010;10(572):1-8. doi:10.1186/1471-2458-10-572

11. Chotboon C, Soontrapa S, Buppasiri P, Muktabhant B, Kongwattanakul Kiattisak TJ, Thinkhamrop J. Adequacy of calcium intake during pregnancy in a tertiary care center. Int J Women's Health. 2018;10:523-527. doi:10.2147/IJWH.S167980

12. INMUCAL. Nutrient calculation software institute of nutrition. Mahidol University. Available from: http://www.inmu.mahidol.ac.th/ inmucal/. Accessed December 31, 2020.

13. Institute of Nutrition, Mahidol University. Nutrient Calcula- Tion Computer Software INMUCAL-Nutrients V.3 Database NB.2 Nakornpathom. 2013. 
14. Ponprachanuvut P, Keeratichamroen A, Chammari K, Srisangwan N. Manual of INMUCAL-Nutrients V.4.0. Salaya. Nakhon Pathom: Institute of Nutrition, Mahidol University; 2019:154.

15. Loy SL, Marhazilina M, Nor Azwany Y, Hamid JJM. Development validity and reproducibility of a food frequency questionnaire in pregnancy for the Universiti Sains Malaysia birth cohort study. Malays J Nutr. 2011;17(1):1-18.

16. Schaafsma A, Deurenberg P, Calame W, et al. Design of the South East Asian nutrition survey (SEANUTS): a four-country multistage cluster design study. Br J Nutr. 2013;110(S3):S2-S10. doi:10.1017/ S0007114513002067

17. WHO. E-Library of Evidence for Nutrition Actions (Elena). Department of Nutrition for Health and Development (NHD); 2011.
18. Aci O, Rathfisch G, García-Miranda R, Moreno-Altamirano L, Solís-Hernández R, Molina-Salazar R. Effect of lifestyle interventions of pregnant women on their dietary habits. lifestyle behaviors and weight gain: a randomized controlled trial. JHPN. 2016;35 (7):1-9. doi:10.1186/s41043-015-0038-5

19. Ghosh-Jeruath S, Devasenapathy N, Singh A, Shankar A, Zodpey S. Ante natal care (ANC) utilization, dietary practices and nutritional outcomes in pregnant an recently delivered women in urban sums of Delhi, India: exploratory cross-sectional study. Reprod Health. 2015;12(20):1-11. doi:10.1186/1742-4755-12-1

\section{Publish your work in this journal}

The International Journal of Women's Health is an international, peerreviewed open-access journal publishing original research, reports, editorials, reviews and commentaries on all aspects of women's healthcare including gynecology, obstetrics, and breast cancer. The manuscript management system is completely online and includes a very quick and fair peer-review system, which is all easy to use. Visit http://www.dovepress.com/testimonials.php to read real quotes from published authors. 